\title{
SUMMARY OF RESEARCH WORK ON THE EVALUATION ON LONG TERM STABILITY OF ARTIFICIAL SLOPE PROTECTION
}

\author{
Ros Soty*1, Dwikorita Karnawati ${ }^{1}$, and Kenji Aoki ${ }^{2}$ \\ ${ }^{1}$ Department of Geological Engineering, Gadjah Mada University, Yogyakarta, Indonesia \\ ${ }^{2}$ Department of Urban and Environmental Engineering, Kyoto University, Japan
}

\begin{abstract}
Application of GPR, RedExplorer1.4 and GeoStudio2004 have been used to evaluate the overall stability condition of a steep slope along Kalibawang irrigation channel $\mathrm{km}$ 8.5, Kulon Progo Regency, Yogyakarta Special Province, Indonesia, that this slope slid down in 1990 and was restabilized by cut to be gentler and covered by shotcrete. Topographic map and engineering geological map in scale 1:2000 have been established prior to the detail investigation. Three drilling logs with in-situ test, SPT and CPT, and samplings have been made and sent to soil mechanic laboratory for index properties tests, and a slope profile along the main axe will be also created for stability analysis through GeoStudio2004. Moreover, GPR has been used to run on a full slope surface to detect the distribution of fractures and/or cavities behind the shotcrete and the results have been interpreted by the aid of RedExplorer1.4.Three profiles showing the rate and depth of fractures and/or cavities are established whereas the slope stability analysis through GeoStudio2004 is the next target of the research. The author is expecting the result from the integration of GPR interpretation and GeoStudio2004 to figure out the overall stability with respect to its existing conditions and its own geometry.
\end{abstract}

Keywords: GPR, GeoStudio2004, overall stability, fracture and/or cavities.

\footnotetext{
${ }^{*}$ Corresponding author: R. SOTY, Department of Geological Engineering, Faculty of Engineering, Gadjah Mada University, Jl. Grafika 2 Yogyakarta, 55281, Indonesia
}

\section{Introduction}

Ground Penetration Radar (GPR) has been recognized by geological engineers as an affective technology which is applicable for shallow subsurface investigation with high resolution. GPR used high frequency pulsed electromagnetic waves to acquire subsurface information. In principal, the energy is propagated downward from the antenna into the ground and reflected back to the earth surface when it touch the contact between two different electrical properties of the material. Basing on its special characteristic, GPR is used to locate objects in the ground such as cables, tanks, pipes, boulders, etc. Furthermore, it can also be used for mapping geological conditions including depth to bedrock and groundwater table, soil/rock thickness and also to detect the cavities or fractures in bedrock. In this research, GPR with antenna $500 \mathrm{MHz}$ is used to detect the distribution of cavities and/or fractures behind shotcrete. The application of GPR and geological engineering investigation method are integrated in order to figure out the stability conditions of the slope. Prior to those, engineering geological investigation method has been also used to study both surface and subsurface condition of the research area aiming to support further analysis for slope stability evaluation. 


\section{Area characteristics}

The research area is located at the steep slope along Kalibawang Irrigation channel $\mathrm{km} \mathrm{8.5,}$ Kulon Progo regency, in the northwest part of Yogyakarta Special Province, Indonesia as indicated in Figure1a. The border of the study area is determined by four coordinates $X_{1}$ : $415.600 \mathrm{~m}, \mathrm{Y}_{1}: 9148.800 \mathrm{~m}, \mathrm{X}_{2}: 415.600 \mathrm{~m}, \mathrm{Y}_{2}$ : $9148.500 \mathrm{~m}, \mathrm{X}_{3}: 416.000 \mathrm{~m}, \mathrm{Y}_{3}: 9148500 \mathrm{~m}, \mathrm{X}_{4}$ : $416.000 \mathrm{~m}, \mathrm{Y}_{4}: 9148.800 \mathrm{~m}$. According to aerial photograph in Figure 1b, the upper part of the slope was cut and covered by shotcrete. Along the toe of the cut slope, there is an irrigation channel with $5 \mathrm{~m}$ width which is covered by concrete and used to be a road in the village. On the top of the slope, there are few old and new houses whereas at the valley of the lower slope there are many settlements. Moreover, the study slope is a small hill which is located between two other small hills. The surrounding areas have different morphologies that the slope degree varies from 18 to $25^{\circ}$ at the north and on the left of the channel composes of slope with 30 to $60^{\circ}$ and the rest are the plane area with different lithologies and geological structures.

Through the aerial photograph, landuse conditions are known and the impact due to slope failure can be predicted such as, irrigation channel, houses and road will be destroyed and people might be also killed. Furthermore, according to existing geological map with scale 1:10000 (Nimol, 2005) Figure 2 the research area composes of Tuff Breccia and Tuffaceous fine Sandstone of Sentolo Formation during early to late Miocene. Several geological investigations have been taken placed in this area in the past years. Few investigations are taken into engineering aspect. Karnawati (2002) made a geological investigation as a part of collaborative research namely Development of Sustainable Slope Protection in Tropical Soil in this area with an engineering geology concentration and her results can be used as the basis of this study. Her result has elaborated the geological condition of this study area as follow:

Kulon Progo Mountains, several isolated hills and colluvial slopes as well as Merapi laharic plain where the Progo River flows are the results of several periods of volcanism and tectonic processes in Java Island which is regarded as a volcanic arc island. After uplifting and erosion, several periods of volcanism led to the deposition of Old Andesitic Formation (OAF) during Oligocene which composes of autoclastic breccia, andesitic breccia, tuffaceous breccia and tuff. Then Jongrangan Formation was formed after other uplifting and erosion during Early to Late Miocene. In the same period, Early to Late Miocene, the last uplifting and erosion process brought about to the Sentolo Formation which consists of fine sandstone, lapilli tuff and tuff breccia. Kalibawang $\mathrm{km} 8.5$ is the exact location and also the research area where Sentolo Formation located. Each formation and location has been shown clearly in geological map Figure 2.

\section{Engineering geological investigation on slope stability}

Landslide can be identified through topographic expression of the terrains. Normally, slope forms and profiles are controlled by lithologic and hydrologic conditions. These components are mainly slope angle, roughness, types of soil/rock, and quantity of runoff by mass movement processes. Still, topographic expression of landslides is a function of slope steepness, height, and the type of slippage being experienced, Rogers, (1989). He also added that in order to discern topographic distortion ascribable to landslide, the map scale must be comparable to the scale of landsliding being evaluated. In other words, the disturbance must be large enough to be noticed on the map. In geological investigation of slope stability, site observation is critical to be conducted. According to Crozier (1984), feature of landform can indicate active and inactive landslide. Slope with scarp, terraces, and crevice with sharp edges or crevice and depressions without secondary infilling show us the active landslide while scarps, terraces, and crevices with rounded edge and crevices and depressions infilled with secondary deposits show the inactive one. 


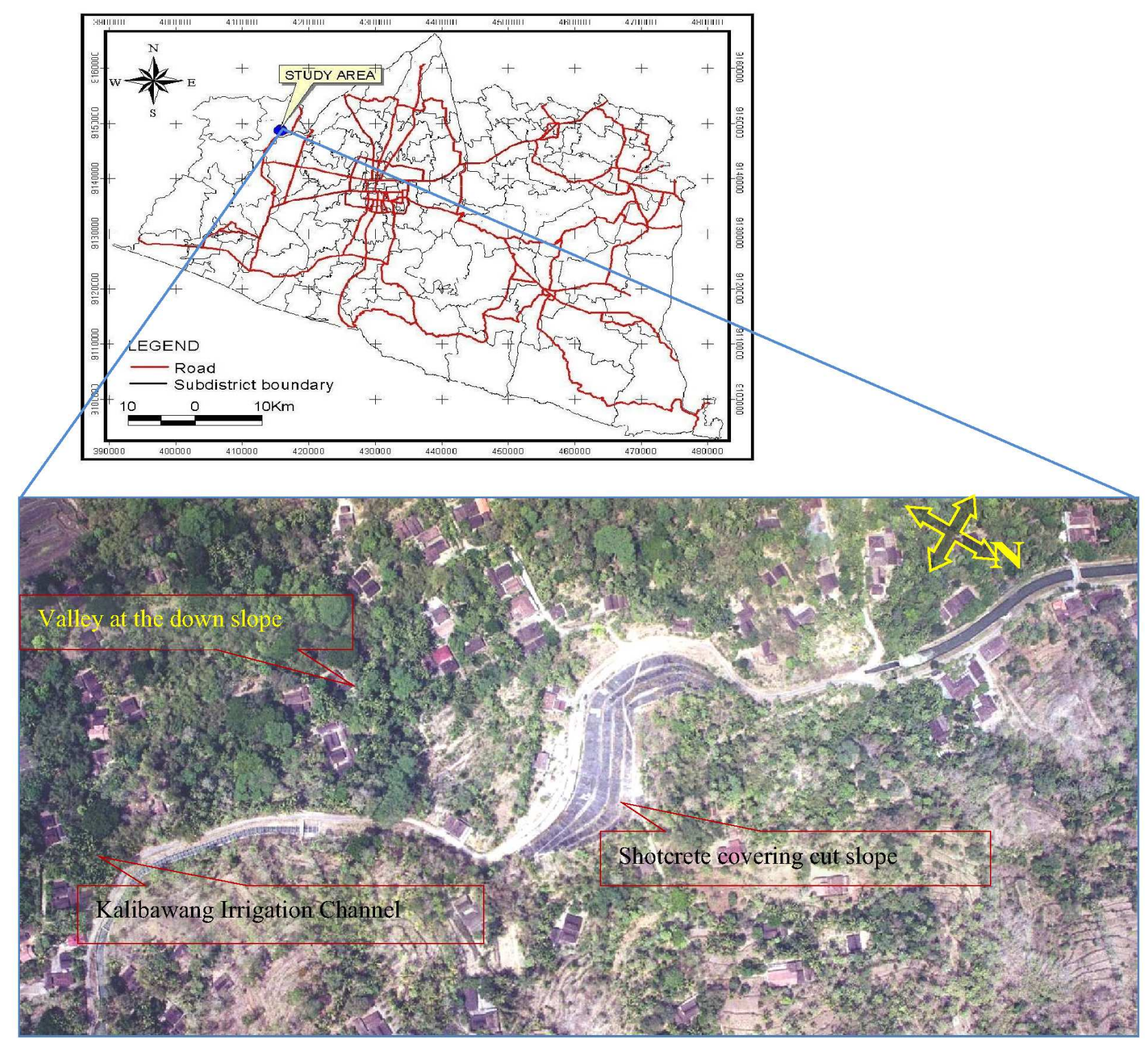

Figure 1: a) Administrative map of Yogyakarta Special Province, Indonesia. b) Aerial photograph of the study area 

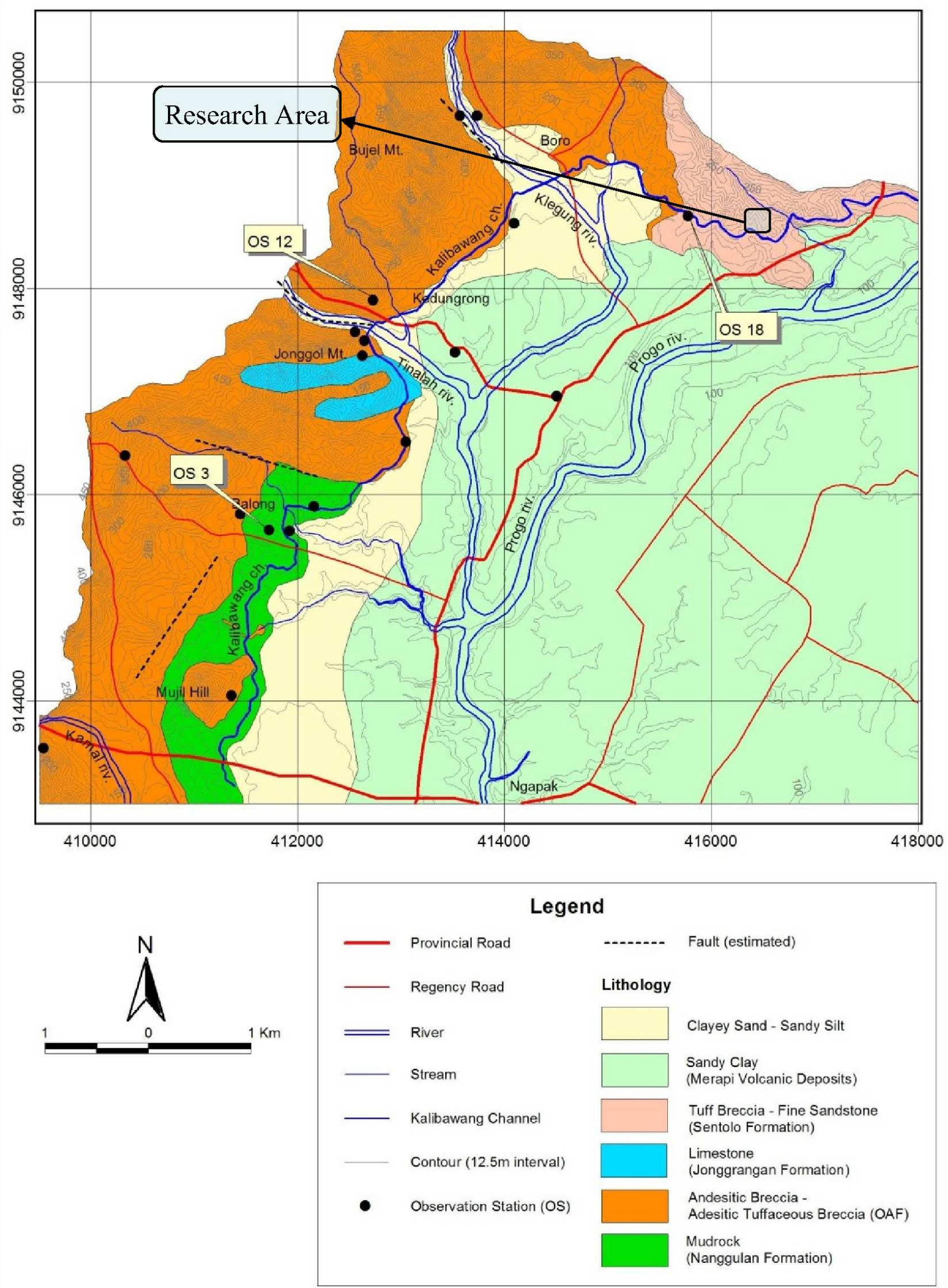

Figure 2: Geological map of the study area (Nimol, 2005). 
On the other hand, tilted trees with no new vertical growth show the active slope comparing with the tiled trees with new vertical growth above inclined trunk. Furthermore, referring to Zaruba and Mencl (1982), tree trunk orientation can often be helpful in assessing the type and decency of movement. Tree might be pushed by ground movement and cause it to lean downhill. If the deflection is not recent, the trunk may curve back in a more upright position several feet above the ground. They also added that in rotational slides, trees that drop in scarp areas or are on the upper portion of a large toe bulge may lean in an uphill direction. In other words, weathering condition should be also taken into consideration, by Blyth and Freitas (1984), tow type of weathering-one is the chemical weathering due to chemical changes; the other is the mechanical weathering as a result of wind, temperature changes, freeze-thaw cycles, and erosion by streams and rivers. Short term and long term stability of slopes may be effected by rate of chemical weathering ranges from a few days to many years, Blyth and Freitas (1984). In addition, mechanical weathering may take years before it has any adverse effect on slopes.

In short, all probable phenomena which could indicate the stability conditions of the study slope need to be interpreted and mapped. Practically, in the stage of engineering geological investigation in this research, surface and subsurface investigation included surficial mapping, drilling work with in-situ test and laboratory test have been conducted which could be described as follow.

Surficial Mapping In this stage, aerial photograph and existing topographic map in scale 1:2000, Figure 3, along with GPS, compass, geologic hammer and other necessary objects have been used to do the mapping. These actions were under taken aiming to record all detail geological conditions that can help us to understand clearly the nature of ground conditions of the study area. Furthermore, during the investigation, several important tasks have been made such as identifying histories of ancient landslides, hydrogeological feature (spring or seepage), available features (geological features, outcrop, etc.), and other usable information for the research. Practically, several stop sites have been made. As a result, few outcrops and two springs were found and engineering geological map in scale 1:2000, Figure 4, was established that can be considered as the primarily results of this research.

Again, the outcrops have been found at SS01, SS-02, and SS-03 that the exact locations are plotted in the topographic map Figure 3. Through careful observation and interpretation, the outcrops compose of Tuffaceous fine sandstone of Sentolo Formation with moderate to high joints/fractures and also moderate to high weathered as illustrated in 5a-c. What's more, at SS-05 and SS-06 at the valley, the lower slope, two springs Photo $2 \mathrm{a}$ and $2 \mathrm{~b}$, have been found. Both springs of water are at the elevation of $130 \mathrm{~m}$ above the sea. The water is seeping out from the contact of clayey sand and tuffaceous breccia. This contact might have the lowest shear strength comparing to other contacts due to high water pressure development and existence of outflow water force. By interviewing people, the water flow out for domestic usage for people living in that area everyday of the year. This situation can lead us suspect that this contact might be the one of the potential slip surface of the suspected slope failures in the research area.

Consequently, engineering geological map in scale 1:2000, Figure 4, has been established. According to this result, the study area is covered by sandy clay and clayey sand which are the results of weathering and erosion processes over tuffaceous breccia and tuffaceous fine sandstone. Clayey Sand spreads in the north part of the studied area while Sandy Clay spread in the south part. Moreover, some parts of the studied slope, Tuffaceous Sandstone can be found also as plotted in the engineering geological map. On the other hand, a main survey lines have been selected as shown in this map. As the advantages, this engineering geological map is the preliminary result of this research leading us to continue to subsurface investigation. 


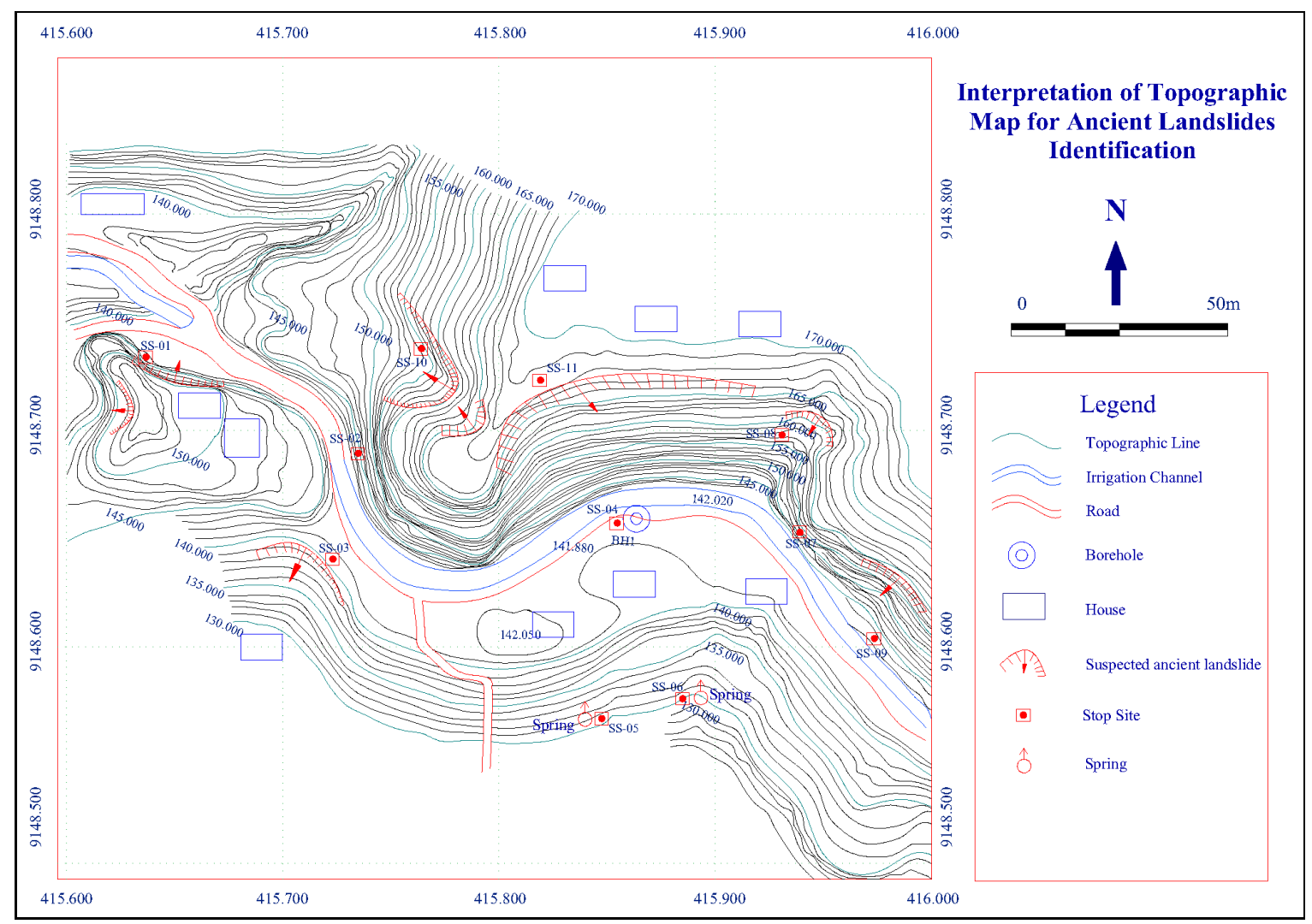

Figure 3: Interpretation of topographic map for ancient landslides identification

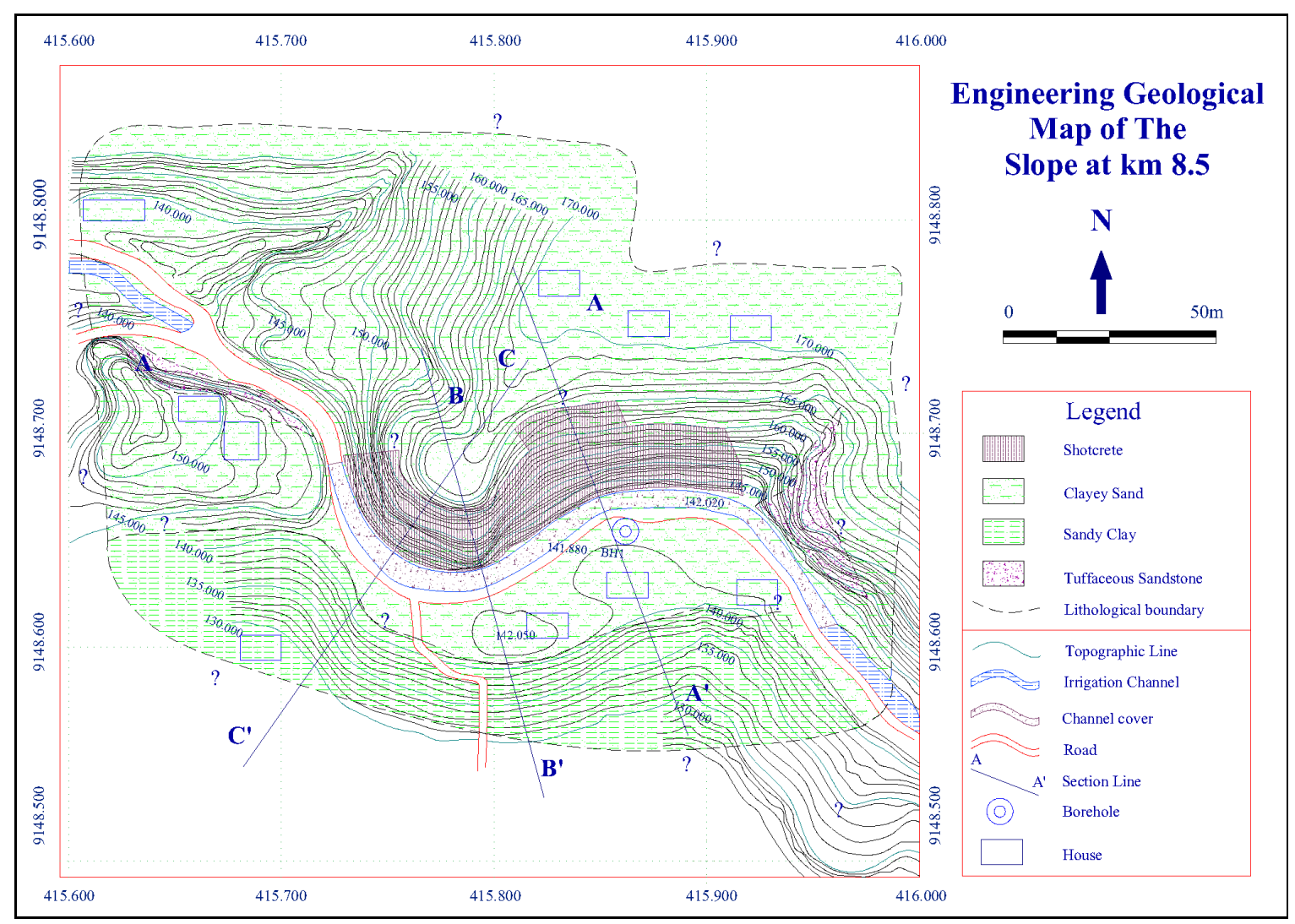

Figure 4: Engineering geological map of the slope at Km 8.5 

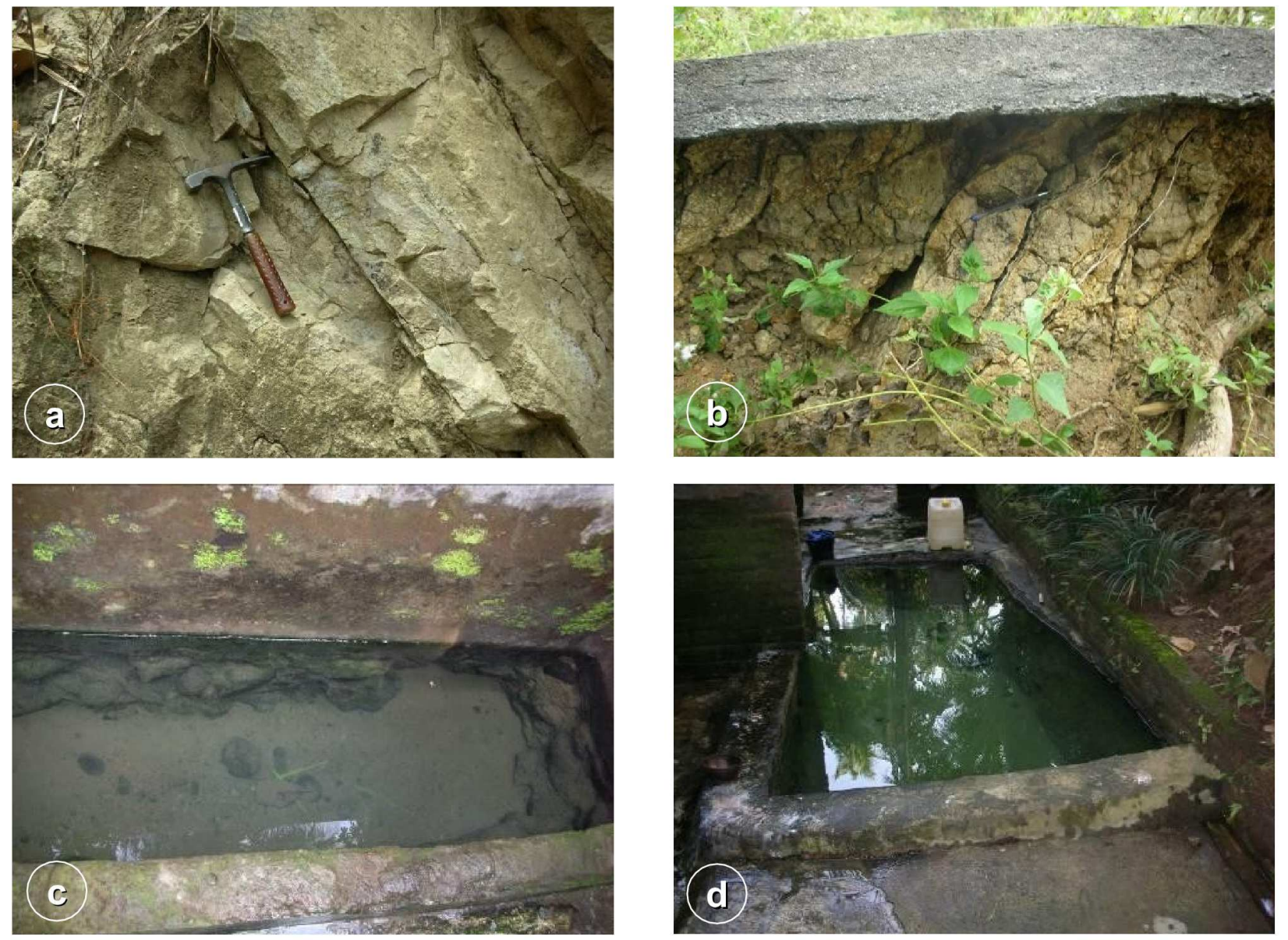

Figure 5: a) Outcrop of slightly weathered tuffaceous sandstone of Sentolo formation, SS-01. b) Outcrop of highly weathered tuffaceous sandstone of Sentolo formation, SS-02. c) Spring at the contact of clayey sandstone and tuffaceous breccia, SS-04. d) Spring at the contact of clayey sandstone and tuffaceous breccia, SS-05 
Subsurface Exploration Subsurface data collection have been done though drilling, sampling and in-situ testing (Standard Penetration Test, SPT). At this stage, the data acquired are the description of the material though out the drilling core. The description will be used for correlation to make the slope profile. On the other hand, Disturbed and undisturbed samples were taken to the soil mechanic laboratory for engineering properties investigation for further analysis.

Boring investigation One drilling hole until $16 \mathrm{~m}$ depth was under taken as indicated in Figure 3. A drilling rig comprising of a rotary drill and simple winch mounted on a tripod. The results from drilling core logging, Table 1, show that the materials are relatively heterogeneous. From 0.00 to $5.70 \mathrm{~m}$ depth we have found brownish white Tuffaceous Fine/Medium Sandstone and Tuffaceous Breccia with greenish white with fragments. These three rock types are slightly loose weak rocks which are high weathered. The permeability is $\mathrm{k}=6.8 \times 10^{-5} \mathrm{~cm} / \mathrm{s}$ from $1-3 \mathrm{~m}$ depth and $\mathrm{k}=5.15 \times 10^{-5} \mathrm{~cm} / \mathrm{s}$ from 3 to $6 \mathrm{~m}$ depth but from 5.7 to $11.30 \mathrm{~m}$ depth we found hard and very hard Tuffaceous Breccia and the color becomes dark white to grayish white with moderate to slight weathering. Furthermore, brownish white Tuffaceous medium and fine Sandstone were found until $14.8 \mathrm{~m}$ depth and continue with Tuffaceous breccia which is compacted and hard.

Standard Penetration Test (SPT) This in-situ test has been partially made due to the fact that some layers are hard that SPT test could not be done. SPT tests were made at depth $2.50-3.00 \mathrm{~m}$, $4.50-5.00 \mathrm{~m}$, and $6.50-7.00 \mathrm{~m}$. During the test, $50 \mathrm{~mm}$ in diameter of split spoon hammer was driving into the borehole by using a $65 \mathrm{~kg}$ hammer fall freely from a height of $760 \mathrm{~mm}$. The numbers of blows falling onto the split spoon are recorded. At initial 150mm depth, the numbers of blows are recorded as a seating blow and for the following $300 \mathrm{~mm}$ depth are recorded as the "N" value (blow count) of the penetration. The numbers of blows are recorded for every
$75 \mathrm{~mm}$ penetration throughout the $450 \mathrm{~mm}$ penetration.

Laboratory Test Result The test has been done for engineering properties of the slope material. The properties are included moisture content, specific gravity, liquid limit, plastic limit, plasticity index, and liquidity index; void ratio, and degree of saturation, coefficient of gradation, internal friction angle and cohesion.

\section{Principle of ground penetrating radar (GPR)}

Ground penetrating radar GPR is one form of radio echo sounding (RES) operating at a frequency between 10 and $1000 \mathrm{MHz}$ (Davis and Annan, 1989) and using a monopulse as transmitted wave which is for relatively shallow penetration. The penetration of 1000 meters depth into the ground has been achieved (Arcone et al. 1995). The system of Ground Penetration GPR units principally composes of a control unit, a transmitter and a receiver which are connected by opto cables in modern systems; and a computer is normally used for data collection. The transmitters and the antennas of transmitter and receiver are changeable at different frequencies for GPR operation. The transmitter generates a very short high voltage pulse and transmits it into the antenna, which emits EMR of a specific frequency into the ground. It transmits a mono pulse i.e. only one wavelength long which has got the shape of a small negative, a large positive and again small negative amplitude. It transmits only one pulse every time and receives a signal from the control unit. The receiver collects incoming signals in samples which are a digital representation of the amplitude and phase of the signal in a certain unit of time. The operating system of GPR from electromagnetic wave input to output can be summarized as in Figure 6 .

During the operation, several samples that have been recorded simultaneously can be put together to a so called stack by calculating their mean value in order to improve a systems ratio between signal and noise. GPR systems transmit a bandwidth of frequencies that is equal 


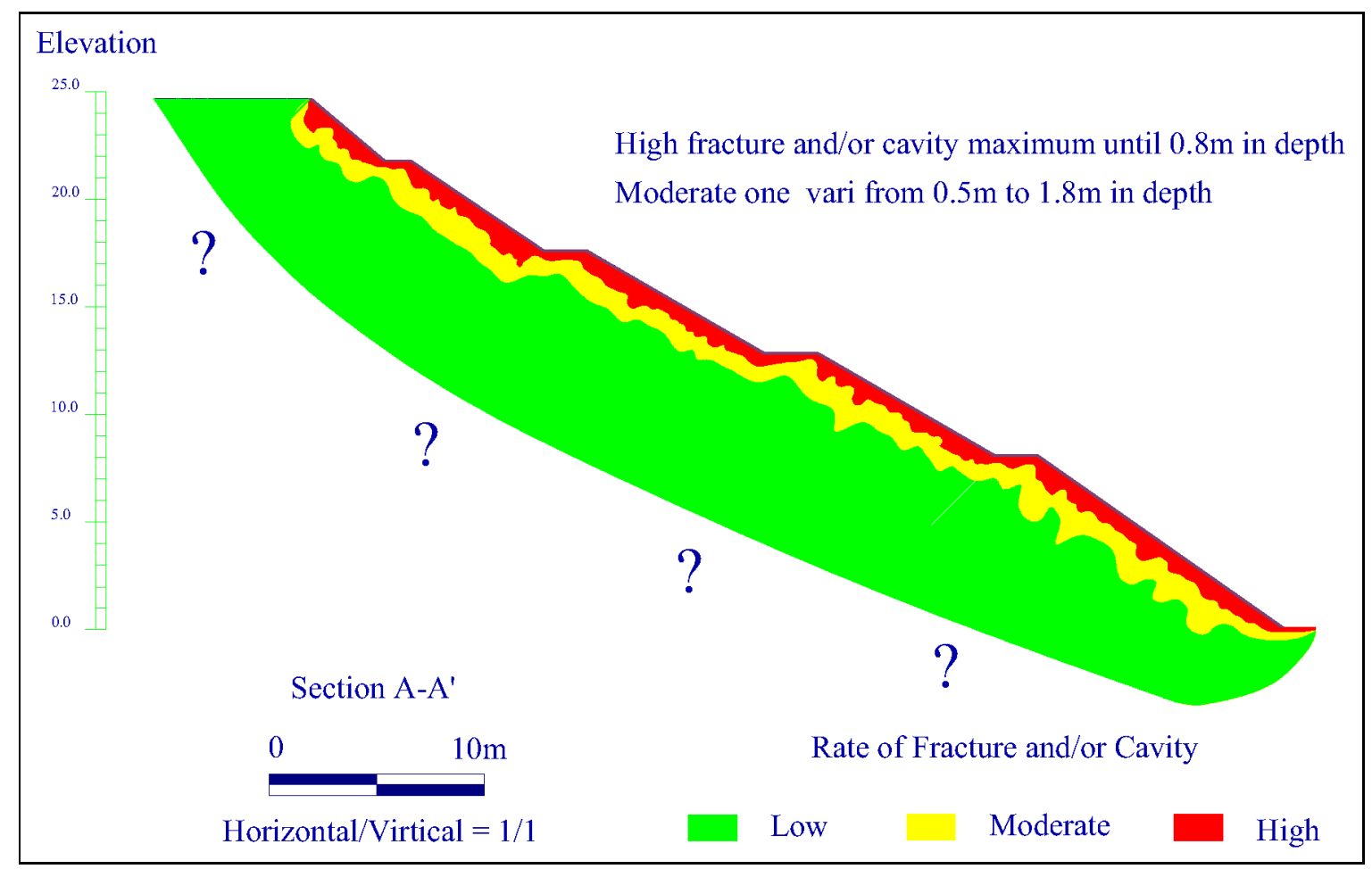

Figure 6: Rate of fracture and/or radargram along axis A-A'

to their centre frequency, the frequency where most energy is emitted. The pulse length is inversely proportional to the centre frequency (Davis and Annan 1989). Increasing frequencies results in an increase of resolution, attenuation and bandwidth as well. This is one reason to make GPR units operable at different frequencies. In radar sounding there is a direct coupling between the antennas of transmitter and receiver. The signal from the transmitter which propagates directly through the air to the receiver is called the air wave. The other part of the direct coupling, the ground wave, travels on the shortest way trough the ground. When separating the receiver from the transmitter, the two components of the direct coupling, air and ground wave can be distinguished as they vary in travel time due to different dielectric constants of air and the ground. Usually transmitter and receiver are placed in a fixed configuration with a defined distance to each other and moved over the ground simultaneously. A hip chain or a wheel measuring the moving velocity of the equipment can be connected to the control unit to guarantee the collecting of data at equidistant positions.

\section{Visualisation of radar data}

While GPR unit is moving over the ground, traces are collected at equidistant positions along the profile. A trace shows the received signal at a position as follows: On one axis the amplitude of the signal and at the other the time the signal needed after the first sample was collected (signal position). This means for reflected signals the time from the transmitter to reflector and from there to the receiver the so called two ways travel time is recorded.

According to Annan and Davis (1976), as the amplitudes of the reflected signal decrease heavily with longer travel times, i.e. greater depth of the reflector, a time variable gain amplifier whose gain increases with return time is applied to the system. It increases linear or exponential as it is required for the specific use due to the fact that the gain can be varied for example at different materials or frequencies. The single traces usually recorded will be transferred into a graphical image called radargram as illustrated in Figure 7 showing the origin of radargram. The horizontal axis hereby displays the antenna position in relation to the starting 
point of the profile. The vertical axis represents a time scale for the radar signal delay time after signal position.

What's more, if the GPR unit is not connected to equipment measuring the right distance for collecting a trace to the previous one, the horizontal axis commonly represents a time scale after the start of the profile collection (Annan and Davis, 1976). One possibility of visualisation is the so called line intensity format where single traces are not displayed and the grey level of the plot gives the amplitude of the signal for individual samples (Acorne et al., 1995).

\section{Result from GPR interpretation}

Ground Penetration Radar GPR with antenna $500 \mathrm{MHz}$ frequency, high resolution, has been operated at site to detect the intensity of fractures and/or cavities behind the shotcrete. Consequently, through the interpreted radargram, there is a very high intensity of cavities and/or fractures on slope material especially near the contact between slope material and shotcrete. Full surface of shotcrete has been divided into a regular pattern for GPR survey. The results of GPR have been interpreted under the help of RedExplorer1.4 and have been depicted on the surface of the shotcrete. Moreover, three slope profile, Figure $6 a, 6 b$ and $6 c$, has been made along three main survey lines $A-A^{\prime}, B-B^{\prime}$ and $C_{-}-C^{\prime}$. These profiles illustrate the rate and depth of fractures and/or cavities behind shotcrete. Furthermore, by observing those profiles, the depths of cavities are locally $1.3 \mathrm{~m}$ while at the shallow depth, around $0.8 \mathrm{~m}$ in depth from the surface of the shotcrete, shows a continuous of very high fractures and/or cavities material. The rate and depth of fracture and/or cavities are divided as high, moderate and low. This result indicates the instability of the slope leading to shallow sliding.

\section{Discussion}

According to the result of surface and subsurface exploration got from the method used as described above, we can discuss the interpreta- tion result from each investigation. Firstly, basing on the upshot of GPR result and interpretation, at the steepness of the studied slope, the material with that continuous high intensity of fracture and/or cavities would slide down at around $0.8 \mathrm{~m}$ in depth. On the contrary, those materials are still residual and stay still due to shotcrete. This condition shows us that, the shotcrete at this time work twice more than at the beginning first is to maintain its own stability covering the surface to the cut slope and second is to stop those high fractures and/or cavities material from sliding down. Consequently, some parts of the shotcrete have slid down. Secondly, from the aftermaths of drilling log and laboratory test, two important conditions should be discussed including both the contact characteristics between lithological types and the engineering properties of the materials.

The contact between clayey sand and Tuffaceous breccia where the spring keep flowing out everyday of the year is suspected to be the potential slip surface due to the consideration on the development of positive pore water pressure and the outflow water force. However the limitation of this contact should be determined. Again, another contact made by the same Tuffaceous breccia but different hardness and rate of weathered is also suspected to be the potential slip surface basing of the consideration on permeability and shear strength values which have been calculated. As a proof, a very low cohesion value comparing to other values, only $0.19 \mathrm{~kg} / \mathrm{cm}^{2}$, of the upper tuffaceous breccia was revealed at $5.70 \mathrm{~m}$ in depth. In addition, the extreme change of the permeability value, from $\mathrm{K}=5.15 \times 10^{-5} \mathrm{~cm} / \mathrm{sec}$ of the upper layer to $\mathrm{K}=2.99 \times 10^{-5} \mathrm{~cm} / \mathrm{sec}$ of the lower one, of weak Tuffaceous breccia to fresh Tuffaceous breccia. Nevertheless, the exact slope profiles are not yet established for further analysis, GeoStudio2004 which will show us clearly how the stability condition and at which contact and depth is the most potential slip surface of the studied slope.

\section{Conclusions}

After a period of time of the surface and subsurface investigation, the distribution and in- 


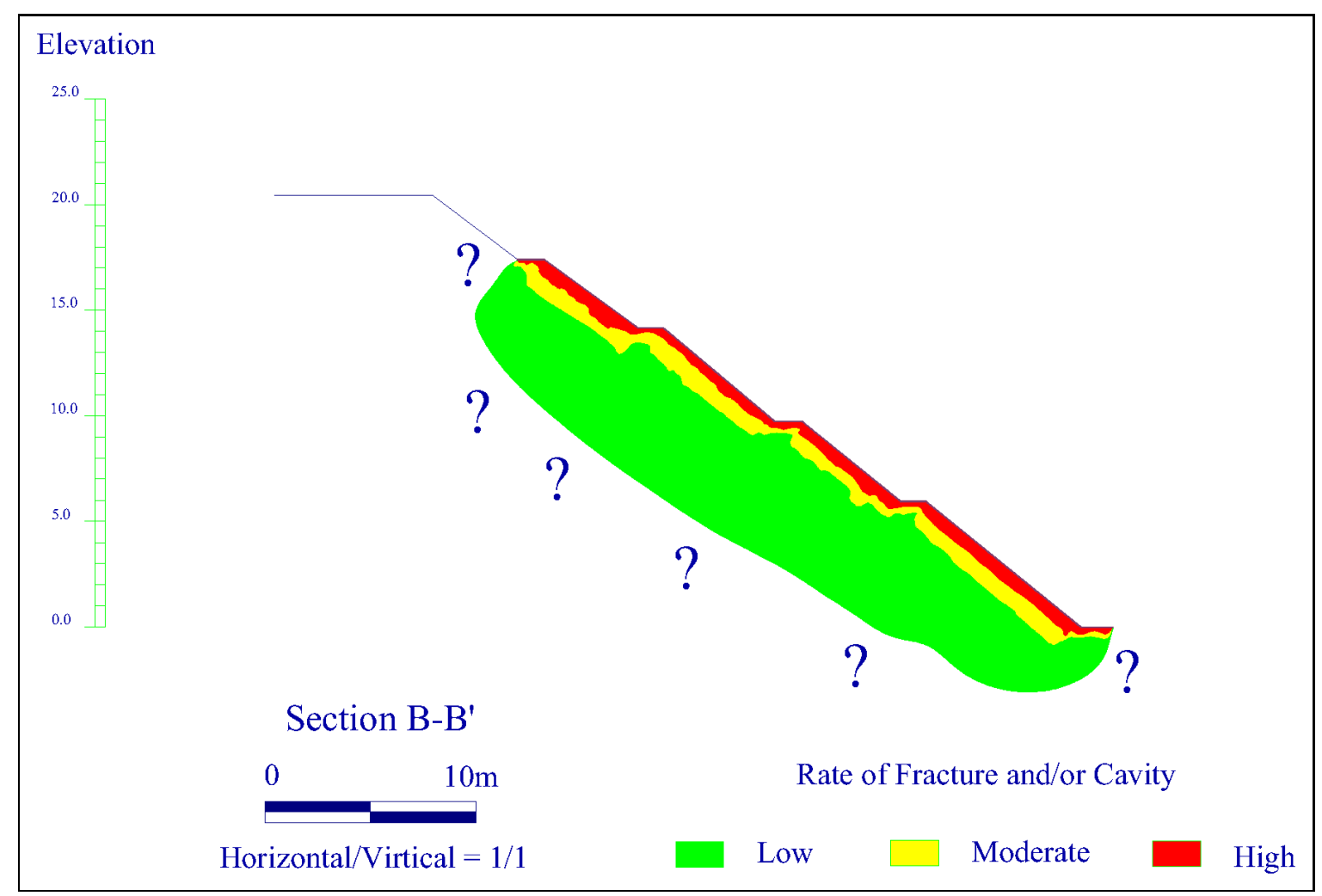

Figure 7: Rate of fracture and/or radargram along axis B-B'

tensity of fractures and/or cavities behind the shotcrete and two suspected potential slip surfaces have been recognized. From GPR results, we can summarize that the fractures and/or cavities at the back of the shotcrete distribute over a full surface with very high intensity and continuously at shallow depth, $0.8 \mathrm{~m}$ from the shotcrete surface. Moreover, the contact where the spring occurs and made from weak tuffaceous breccia and fresh tuffaceous breccia are still unclear to be the most unstable surface due to the face that it need be analyzed more clearly though GeoStudio2004 to know exactly the value of safety factor of each surface. However, these results still can be used as a preliminary conclusion of the research. Last but not least, the author strongly believes that the overall stability of the researched slope will be revealed after an exact slope profile with dipping bedded have been made and analyzed though the available numerical simulation, GeoStudion2004, which is the final step of this research.

\section{References}

Annan, A.P. and Davis, J.L. (1976) Impulse radar sounding in permafrost. Radio Science 11, 1976. pp. 383-394.

Acorne, S.A., Lawson, D.E., and Delaney, A.J. (1995) Short-pulse radar wavelet recovery and resolution of dielectric contrasts within englacial and basal ice of Matanuska Glacier, Alaska, U.S.A. Journal of Glaciology 41 (137), 1995. pp. 68-86.

Blyth, F. G. H., and Freitas, M. H. (1984) A Geology for Engineering, 7th ed., London. English Language Book Society.

Crozier, M. J. (1984) Filed Assessment of Slope Instability, D. Brunsden and D.B. Prio, Eds. New York: Wiley.

Davis, J.L., and Annan, A.P. (1989) Groundpenetrating radar for high resolution mapping of soil and rock stratigraphy. Geophysical Prospecting 37, 1989. pp. 531-551.

Karnawati, D., (2002) Basic Concept on Landslide Mapping, Department of Geological Engineering, Gadjah Mada University. Unpublished

Nimol, V. (2005). Application of Geographic Information System (GIS) for Landslide Susceptibility Mapping from Km 6 to $\mathrm{Km} 19$ of Kalibawang Irrigation Channel. Unpublished M.Sc. Thesis, Ge- 
ological Engineering Department, Gadjah Mada University, Yogyakarta, Indonesia.

Rogers, D. (1989) Topographic Expression of Landslide-Prone Terrain, Reprint from the 9th National Short Course on Slope Stability and Landslides, San Diego, California.
Zaruba, Q. and Mencl, V. (1982) Landslides and Their Control. New York: Elsevier Scientific. 